\title{
Influence of Sex and Age on Depression among First Year Undergraduates of Faculty of Education in Cross River State, Nigeria
}

\author{
Joy Nwaobiara Njoku
}

\author{
David Onwe Igbodor \\ Melvina N. Amalu \\ Department of Educational Foundations, \\ University of Calabar, \\ Etagbor, PMB 1115 Calabar 2018, Nigeria
}

Doi: 10.36941/mjss-2020-0o18

\begin{abstract}
This study was on the influence of sex and age on depression among first year undergraduates in Cross River State, Nigeria. The population of the study was 2,80o first year students of the two Universities in Cross River State (University of Calabar and Cross River State University of Science and Technology). A sample of 560 first year students was drawn from the institutions to take part in the study using random sampling technique. This comprised of 269 males and 291 females. A questionnaire with two sections was used for data collection. Section A, elicited responses for sex and age while section $B$ was an adapted Beck's depression inventory to gather information on the degree of depression among the students. The statistical tools used were the independent $t$-test and ANOVA. T-test was used to analyze responses on sex while the ANOVA was used to analyze responses on age and depression. The results showed that the males were more depressed than the females and depression also increased with age.It was recommended among other things that parents and sponsors of these students should show equal care in terms of giving upkeep money to both the males and the females. People should also be encouraged to go to school at early age.
\end{abstract}

Keywords: Influence, Age, Sex, Depression Undergraduate

\section{Introduction}

Depression is one of the most common mood disorders identified in human. It is classified among psychiatric illness depending on its severity. A functional and active human being experiences a swing of depressive mood at one point in life or the other as the struggle for survival continues on daily basis. The ability to overcome this mood swing and positively continue in daily task is a sign of good mental health.

The degree of depression in someone can be influenced by biological and environmental factors.Environmental factors include home pressure, academic challenges while biological factors are in terms of hormonal changes and genetic make up.Some of the signs of depression include social withdrawal, reduced energy, feeling of guilt, lack of concentration, poor appetite, sleeplessness, uncoordinated speech, sadness, anxiety, suicidal threats, over indulgence in alcohol and tobacco, increased heart beats and so on. Arakhami (2013) identified depression as the most widespread 
mental health problem across the world. Ibrahim, Kally, Adams and Glazebrook (2003) also assessed depression to be the most prevalent mental health problem among undergraduates.

Depression among University students could be prevalent and widespread problem across the country (Abedimi, Davachi, Sohbaee, Mahmoodi and Safa, 2007). Among students depression presents in a state of law mood, withdrawal from normal and interesting activities, absent from lectures, rudeness, substances abuse, poor concentration and so on. This can affect the totality of the student's behavior and well-being.

In a developing country like Nigeria, students having swings of depressive mood is inevitable but when it is allowed to be severe it becomes major psychological problem. First year undergraduates are faced with major adjustment problems in schools. Some of them are leaving home for the first time and are faced with the challenge of solving their problems by themselves. They are faced with higher level of academic work and the challenge of choosing their friends and associates. Many successfully adjust and fit into the new role expectations while some fail and slide into depression. An instance is the case of a 10o-level student who committed suicide at the University of Nigeria Nsukka on $14^{\text {th }}$ of May 2018. He left a suicide note which reads "forgive me, in case you are the one who found the body. I am really sorry, it had to be someone you know". This student drank two bottles of insecticide called sniper to end his life. This is just one case out of many. Parents are trying their best to sponsor and keep these students happy to face their academics, the government is also trying to subsidize tuition for the undergraduates yet many students particularly first year undergraduates still find it difficult to cope hence they slide into depression. What could be the major factors influencing this depressive tendencies? This and some other questions have led the researchers to investigate the influences of two demographic variable; sex and age in this research. Sex in this research is considered to be the biological make-up of males and females. Sex here implies the natural identification of the male and the female by their physical composition.

Karen (2018) frankly noted that the definition of sex and gender is becoming increasing difficult. Before the two words were used interchangeably but now each of them is assuming a more distinct meaning from the other. John (2017) defined sex as biological characteristics of males and females in the forms of hormones, genital appearance and functions while gender is defined in terms of roles of males and females which sometimes may not strictly apply to the sex of an individual. Karen (2018) explained gender in relation to social and cultural roles of each sex rather than genetic as sex demotes. The researchers therefore wish to investigate the influence of sex on depression of first year undergraduates.

Many believe that the nature of females predisposes them to anxiety and some other characteristics that may depress them if not checked. However many females have proved to be as capable as males in tackling life challenges. Nazroo (2001) in their research found out that women were at more risk of depression in America and the same applied to British women. The issue of sex may not be a real reason for their depression, the researchers also wish to investigate the influence of age on depression among the first year undergraduates.

Age in this research connotes the number of years a person has lives from birth. It is chronological time frame someone has lived. In Nigeria someone can enter the university at the age of 16. The official age to commense University education is 16 years. The researchers have categorized age in this research from 16-20, 21-25, 26 and above. Some people believe that maturity comes with age. Which means that one should be capable of tackling life changeless with age? This assertion however is not true with the report of WHO (2015). They reported from their research that American adolescents aged 16 to 17 were more than twice likely to report major depressive episodes compared to those aged 12-13 years. Depression cannot be easily linked to a single social, biological or environmental factor, it is necessary to assess various factors an individual who has this tendency may be dealing with in order to plan coping strategy. The objective of this research work is to investigate the influence of sex and age on depression among first year undergraduates in Cross River State, Nigeria. Depression has been classified into minimal, mild, moderate and severe.

To address the objectives of this research,two research questions were posed; 
(i) What is the difference in the degree of depression among males and females first year undergraduates of Cross River State, Nigeria.

(ii) To what extent does age influence the degree of depression among first year undergraduates of Cross River State, Nigeria.

In the same vein two null hypotheses were formulated to guide the study;

(i) There is no significant difference in the degree of depression among male and female first year undergraduates of Cross River State, Nigeria.

(ii) There is no significant influence of age on depression among first year undergraduates of Cross River State, Nigeria.

This research is anchored on the cognitive theory of Depression by Aaron T. Becks (1967). It is from this theory that Beck's Depression inventory which was adapted for this study was generated. Beck (1967) studied people suffering from depression and found out that they appraised situations and events in a negative way. He identified three mechanisms responsible for depression to be;

(a) Negative automatic thinking (cognitive trial)

(b) Negative self schemes

(c) Errors in logic, that is faulty information processing.

Beck emphasized that depressed people tend to view themselves as helpless, worthless, and inadequate. They see the world as posing threats and obstacles that cannot be handled. They see the future as totally helpless with nothing to desire. This is why they are always sad and quick to try suicide. The negative self schemes could be as a result of traumatic experience like loss of parents, siblings, rejection, critism, neglect, abuse and bullying at school.

\section{Statement of Problem}

As globalization and technological development continue to increase, human expectations and targets also increase. Everybody wants to meet up with expectations and this has resulted to various degrees of psychological, physical and mental challenges which depression is key. First year undergraduates are mainly adolescents who maybe leaving the comfort of their homes for the first time. They find themselves in campuses to be in charge of their own success and failure. Many of them successfully go through it but many become frustrated and go into depression. Depressive symptoms and activities have been manifested by a number of these students in various campuses of tertiary institutions. Some look sad and moody, some disconnect from families and friends and go into drugs, some attempt suicides while others have succeeded in taking their own lives. In May 2018 a 10o-level student took his life and dropped a suicide not in one of the campuses. The effort of parents and school authorizes to help students feel relaxed in schools and study have not yield the expected result. This has prompted the researchers to think deep into what could be factors promotion this unfortunate situation. Considering the impact of sex and age on adolescents the researchers deemed it necessary to investigate the influence of these two variables on depression among these students.

\section{Research Method}

The researchers adopted expost factor design for this study. This design is suitable for this research because there is no room for the researcher to manipulate the independent variables (sex and age). They have naturally occurred before the research was conducted.

Simon and Goes (2013) also recommended the use of expost factor for certain non-experimental studies that seek to determined the influence of one variable on the other. This research was carried out in Cross River State, Nigeria which has two Universities. One Federal University (University of Calabar) and one State University (Cross River State University of Science and Technology). The population of the study was 2800 first year undergraduate from the two Universities in 2017/2018 academic session. University of Calabar had 1,55students while Cross River State University of Science and Technology had 1,249 students. 
Table 1: Population of first year's students by school and sex in 2017/2018 session

\begin{tabular}{clccc}
\hline S/N & Name of School & Male & Female & \\
\hline 1. & University of Calabar & 725 & 726 & 1,551 \\
2. & Cross River State University & 597 & 652 & 1,249 \\
& Total & 1,322 & 1,478 & 2,800 \\
\hline
\end{tabular}

Source: Academic Planning Unit of each University 2017/2018

Purposive and random sampling techniques were adopted for the study. The two Universities in the State and Faculty of Education of each of the Universities were purposively selected. Faculty of Education was selected because they had the needed population for the study. Random sampling technique was used to select $20 \%$ of the first year students in each of the institutions. Twenty percent $(20 \%)$ of the population in each institution was used so that there will be even representation from each school. From University of Calabar 310 students were randomly selected while 250 students were selected from Cross River State University of Science and Technology (CRUTECH). A total sample of 560 students participated in the study, comprising of 269 males and 291 females. Females are more than the males in Faculty of Education because they are more interested in the teaching profession than the males.

The instrument used for data collection was questionnaires. The questionnaires comprised of two sections. Section A elicited responses for demographic variables like sex and age while section B was adapted Beck's Depression Inventory (1967).

Beck's Depression Inventory is one of the most widely used psychometric tests for measuring the severity of depression. It originally comprised of 21 items self-report inventory but for the purpose of this study one of the items that was purely on marital relationship was dropped since it is not necessary for the category of respondents. By this adjustment, the instrument had 20 items. This instrument was judged by experts in Educational psychology and Measurement and Evaluation to have good face validity. A test retest approach was carried out on 50 students in another faculty that was not part of the study within an interval of two weeks. Pearson Product Moment Correction Coefficient was used to analyze the data gathered from the pilot test. A reliability coefficient of .78 was obtained. By this the instrument was judged to be reliable for the study.

The instrument had a scoring guide with scale ranging from $0-3$

In the scoring guide, Minimal scores (o), Mild (1), Moderate (2) and Severe (3). At the end of the collation of the data, the degree of depression was determined by the following classification.
(i) Minimal
(o - 9)
(ii) Mild
$(10-18)$
(iii) Moderate
$(19-29)$
(iv) Severe
$(30-60)$

Tables 2: Coding Schedule for the instrument

\begin{tabular}{lllc}
\hline Variables & Code & & Column \\
\hline Sex & Male & 1 & 1 \\
Age & Female & 2 & \\
& $16-20$ & 1 & 2 \\
& $21-25$ & 2 & \\
Depression & $26-$ above & 3 & 3 \\
& Minimal & 0 & \\
& Mild & 1 & \\
\hline
\end{tabular}


The researcher distributed the questionnaires in the respective schools and collected them from the students after their responses. The students knew what was required of them and they co - operated by answering the questions as it applied to them. The researcher collated the responses and coded them for analyses.

The analysis was done using the statistical tool suitable for each null hypothesis.

Hypothesis one which sort for information on differences between the males and females on the degree of depression was analyzed using the t-test.

Hypothesis two was analyzed using the ANOVA because age was in categories.

\section{Results}

\subsection{Hypothesis one}

There is no significant difference in the degree of depression among males and females first year undergraduate of Faculty of Education in Cross River State, Nigeria.

Table 3: Independent t-test analysis of sex and depression among first years undergraduate in Cross River State, Nigeria.

\begin{tabular}{lccccc}
\hline Sex & $\mathrm{N}$ & $\overline{\mathrm{X}}$ & $\mathrm{SD}$ & t-value & P-level \\
\hline Male & 269 & 40.84 & 9.10 & \multirow{2}{*}{5.211} & \multirow{2}{*}{.ooo } \\
Female & 291 & 36.75 & 9.48 & \multirow{2}{*}{. }
\end{tabular}

Significant at $.05 ; \mathrm{df}=558$

The result in Table 3 revealed that the mean score for males as regards to the degree of depression was 40.84 with standard deviation of 9.10 while the mean score from females was 36.75 with standard deviation of 9.48. These values were significantly different. The t-value of 5.2111 with P-value of .ooo also met the criteria for significant at .05 level. This results shows that there is significant difference in the degree of depression between the male and female students, with male students being more depressed than the females.

The null hypothesis is therefore rejected.

\subsection{Hypothesis 2}

There is no significant influence of age on depression among first year undergraduates in Cross River State, Nigeria.

Table 4: One-way Analysis of variance of age and depression among first year University undergraduates in Cross River State, Nigeria.

\begin{tabular}{|c|c|c|c|c|c|}
\hline Age & & $\mathrm{N}$ & $\overline{\mathrm{X}}$ & & SD \\
\hline $16-20$ years & & 165 & 33.75 & & 10.60 \\
\hline $21-25$ years & & 286 & 39.75 & & 7.75 \\
\hline 26 years and above & & 109 & 43.50 & & 8.68 \\
\hline Total & & 560 & 38.71 & & 9.51 \\
\hline Source of variance & Sum of squares & $\mathrm{df}$ & Mean squares & F-ratio & p-level \\
\hline Between groups & 6861.202 & 2 & 3430.601 & 43.728 & .000 \\
\hline Within groups & 43697.934 & 557 & $78.45^{2}$ & & \\
\hline Total & 50559.136 & 559 & & & \\
\hline
\end{tabular}

*Significant at .05 alpha level

The result on Table 4 showed that the calculated F-ratio obtained was 43.728 while p-value was .ooo 
with 2 and 557 degrees of freedom. This result is considered significant so the null hypothesis which stated that there is no significant influence of age on depression of first year undergraduates in Cross River State was rejected. A closer look at the result showed that the mean scores increased with age. This shows that the older students were more depressed than the younger ones.

\section{Discussion of Findings}

The results of this study revealed that male first years students in Cross River State, Nigeria were more depressed than their female counter parts. This result is contrary to the findings of many studies particularly in the Western World. Sharpley and Melhem (2010) conducted a research on gender differences in anxiety and depression among Australian University Students. They found females to be more depressed than the males.In the same vein Nazroo (2010) studied 97 couples from Britain and discovered marked difference in depression with females being more depressed. Their key reason for this differences were mainly linked with biological functions and compositions like hormonal inbalances in females. However this present study investigated on different category of people in age, social life, culture and background.

The rate of expectation on the male children by their parents and family members in this part of the world expose them to high level of anxiety and worry. They are conscious of the fact that much is expected of then and they want to make it at all costs. Some of the male students cater for themselves in schools, doing various menial jobs to survive but the female students are often protected and provided for so they study under more relaxed atmosphere than their male counter parts. Biological changes are normal occurrences the girls can cope with but lack and deprivation can lead to depression.

It has also been noted that the males are more into substance abuse than the females. Obogo and Njoku (2017) in their study with Senior Secondary School, Students in Calabar on gender, depression and drug abuse lamented a high rate of drug abuse particularly among the male students. Drugs can alter the Chemistry of the body and result to problems that can lead to depression. Cultism among the students has become a thing of serious concern in schools and this is more with the male students who go all out to recruit the first year male students into their gangs and sometimes when they refuse to join they run the risk of abandoning their studies to run for their lives. These social deviations can keep a student very anxious and worried which can eventually lead to depression.

The study also revealed that the older students 26 years and above were more depressed than their younger counter parts.This result tally with the findings of some other researchers like Naushad, Farooqui, Sharma, Rani, Singh and Verma (2010) who invested the prevalence of depression and its severity among pre-university students in Mahgalorecity. They found that depression increased with age. In the same way Bostancietal., (2005) in their study also found the older student more depressed than the younger ones. On the contrast some researcher like Tomada, Mori, Kinura, Takahashi and Kotamura (2000) in the study using University students in Japan found that the younger students were more depressed than the older one. Some found no significant influence of age on depression. The result of this study which found older students more depressed than the younger ones could be explained by the degree of expectations and responsibilities the older students are exposed to. This can make them not to concentrate in the schools. If they can not cope with the studies they may go into depression.

\section{Conclusion}

Depression is a mental health condition characterized by feeling of sadness, guilt,lack of concentration, poor appetite, reduced energy, anxiety, suicidal threats, social withdrawal, over indulgence in substances and sleeplessness. It is common among students particularly first year undergraduates. Depression is evident in males than females in Cross River State and also increases with age among the students. With the findings of this study, depression may not only be associated 
with biological composition and functioning of an individual. There may be other variables in males that pre-dispose them to depression more than their female counter parts.

\section{Recommendations}

The researchers after discussing the findings of this study came up with the following recommendations.

(1) Parents should show equal love and care to both male and female children in terms of giving monthly allowances so that they can relax and face their studies.

(2) People should be given opportunity to go to school at early age to help them concentrate well.

(3) Institutions should create avenues for the students to share their burdens and worries.

(4) There should be regular seminars and talks on the need for positive mental health among students.

\section{References}

Abedini, S., Davachi, A., Sohbace, F., Mahmood, M., \&Safa, O. (2017).Prevalence of depression in nursing students in Hormozgan University of Medical Sciences.Hormozgan Medical Journal,11(2), 139 - 145.

American Psychiatric Association (2013).Diagnostic and statistical manual of mental disorders, DSM-5, $5^{\text {th }}$ Ed, Washington DC.

Beck, A. T. (1967).Becks Depression Inventory. Twenty five years of evaluation. Clinical Psychology Review, 1, 77100.

Bostanci, M., Ozdel, O., Zhanoglu, O., Ozdel, L., Ergin, A., Ergin, N., \&Karadag, F (2005). Depression Symtomatology among University students, Denizli, Turkey.

Ibrahim, A. K., Kelly, S. J., Adam, C. E., \&Etazebrook, E. (2013).A systematic review of studies of depression prevalence in University students.Journal of PsychratricResearch, 47.

John, S. (2017). What is the difference between sex and gender?http://sciabc.us/gkb3u, retrieved 4/11/2019.

Karen, C. (2018). Sex and gender what is the difference. Medical news today, Health line media UK Ltd, Brighton UK.

Marilyn, K. S., \& Jim, G, (2013). Ex post Facto Research. Dissertation and scholarly Research, recipes for success, WA, Dissertation Success LLC www.dissertationrecipes.com

Naushad, S., Farooqui, W., Sharma, S., Rani, M., Singh, R., \&Verma, S. (2010). Study of proportion and determinants of depression among college students in Mangalore City.Nigeria Medical Journal, 55 (2), 156 160.

Nazroo, J., Edward, A., \& Brown, G. (1998). Gender differences in the prevalence of depression.Artifact alternative disorder, biology or roles?Sociology of health illness, 20, $312-330$.

Obogo, G. O., \&Njoku, J.N. (2017). Gender, depression and drug abuse among Senior Secondary School Students in Calabar Education Zone, Cross River State, Nigeria. European Journal of Education Studies, 3 (1), 387 - 395.

Sharma, V. (2014).Effect of gender and stream on depression among adolescents.International Journal of Education and Psychological Research, 3 (2), 46 - 49.

Tomado, A., Mori, K., Kiniura, M., Takahashi, T., \&Kotamura, T. (200o). Prevalence and incidence of depression among first year university students in Japan, A preliminary study, Psychiatry and clinical neuroscience.

World Health Organization (2013).Gender disparities in Mental Health, WHO, Geneva. 